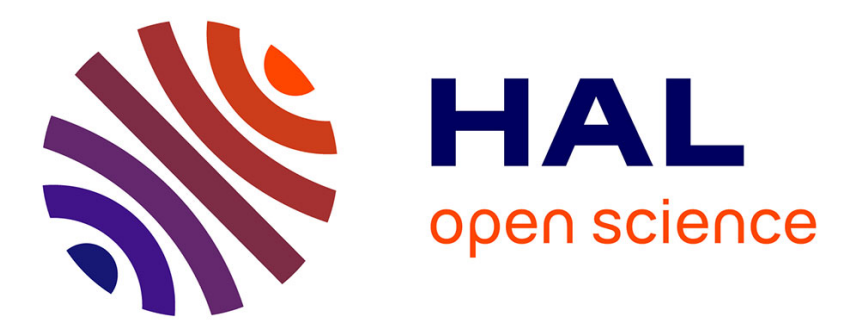

\title{
Acid/base front propagation in saturated porous media: 2D laboratory experiments and modeling
}

\author{
Stéphanie Lawniczak, Francois Lehmann, Philippe Ackerer
}

\section{To cite this version:}

Stéphanie Lawniczak, Francois Lehmann, Philippe Ackerer. Acid/base front propagation in saturated porous media: 2D laboratory experiments and modeling. Journal of Contaminant Hydrology, 2012, 138-139, pp.15-21. 10.1016/j.jconhyd.2012.06.005 . hal-03049674

\section{HAL Id: hal-03049674 \\ https://hal.science/hal-03049674}

Submitted on 9 Dec 2020

HAL is a multi-disciplinary open access archive for the deposit and dissemination of scientific research documents, whether they are published or not. The documents may come from teaching and research institutions in France or abroad, or from public or private research centers.
L'archive ouverte pluridisciplinaire HAL, est destinée au dépôt et à la diffusion de documents scientifiques de niveau recherche, publiés ou non, émanant des établissements d'enseignement et de recherche français ou étrangers, des laboratoires publics ou privés. 
1 Acid/base front propagation in saturated porous media: 2D laboratory experiments and modeling.

4 Stéphanie Loyaux-Lawniczak, François Lehmann and Philippe Ackerer*

6 Laboratoire d'Hydrologie et de Géochimie de Strasbourg,

7 Université de Strasbourg/EOST - CNRS,

81 rue de Blessig, 67000 Strasbourg,

9 France.

\section{Abstract}

We perform laboratory scale reactive transport experiments involving acid-basic reactions between nitric acid and sodium hydroxide. A two-dimensional experimental set-up is designed to provide continuous on-line measurements of physico-chemical parameters such as $\mathrm{pH}$, redox potential (Eh) and electrical conductivity (EC) inside the system under saturated flow through conditions. The electrodes provide reliable values of $\mathrm{pH}$ and $\mathrm{EC}$, while sharp fronts associated with redox potential dynamics could not be captured. Care should be taken to properly incorporate within a numerical model the mixing processes occurring inside the electrodes. The available observations are modeled through a numerical code based on the advection-dispersion equation. In this framework, EC is considered as a variable behaving as a conservative tracer and $\mathrm{pH}$ and Eh requires solving the advection dispersion equation only 
once. The agreement between the computed and measured $\mathrm{pH}$ and $\mathrm{EC}$ is good even without 2 recurring to parameters calibration on the basis of the experiments. Out findings suggest that 3 the classical advection-dispersion equation can be used to interpret these kinds of experiments 4 if mixing inside the electrodes is adequately considered.

5

6 


\section{Introduction}

3 Modeling reactive transport of dissolved species in porous media is considered essential in

4 Earth sciences and has been the subject of several investigations (e.g., Steefel et al., 2005 and

5 references therein). Prediction of migrating reactive chemicals (including, e.g., heavy metals,

6 organic species from industrial solvents, products from mining, agrochemicals,

7 petrochemicals) is also of paramount concern for the protection, management and remediation

8 of groundwater resources.

9 Several numerical techniques and codes have been developed to simulate reactive transport processes in natural groundwater systems (Kinzelbach et al., 1991; Yeh, \& Tripathi, 1991; Walter et al., 1994; Saaltink et al., 2001; Van der Lee et al., 2003; Fahs et al., 2009 among others). The mechanisms involved in reactive transport processes are often strongly non-linear and occur on a multiplicity of time scales, thus rendering the solution of a mathematical model very challenging. Verifying and assessing the robustness of numerical models can be performed by benchmarking. However, recent results have shown that different numerical schemes and codes can produce different results for the same benchmark problem even under apparently simple one-dimensional scenarios (Carrayrou et al., 2010).

Assessment of the reliability of conceptual schemes and associated computational models can also be performed through controlled experimental investigations at the laboratory scale. There is a vast literature devoted to analyzing experiments performed within seemingly one-

21 dimensional porous systems, obtained by packing granular material within columns of 22 different length scales (Burris et al., 1996; André et al., 1998; Gandhi et al., 2002; Gramling et al., 2002; Su \& Puls, 2004; Grolimund \& Borkovec, 2006, among many others). Twodimensional set-ups have been used only recently to observe key features of reactive transport experiments, with special emphasis on transverse mixing processes in the presence of fluids 
1 with different water compositions. Experiments have documented the precipitation pattern of

2 a calcium carbonate solid phase (Katz et al., 2010), concentration distributions in

3 heterogeneous density-driven flow systems (Konz et al., 2009a), biodegradation of toluene

4 (Bauer et al., 2008), and transverse mixing in heterogeneous porous media (Rolle et al., 5 2009).

6 Detailed reactive transport experiments are also required to improve our understanding of the 7 main features of spreading and mixing processes affecting solutes migration at different 8 scales. Characterization of conservative or reactive transport via Fickian or non-Fickian 9 models is still an open debate. For example, the reactive transport experiments of Gramling et al. (2002) involving an irreversible bimolecular reaction could be interpreted by particle 11 tracking methods relying on non-Fickian solute behavior (Edery et al., 2009, 2010) or by 12 solving a continuum model based on the standard advection-dispersion-reaction equation 13 (ADRE) with a time-dependent macro-scale kinetic term describing mixing of solutes at the small scales (Sanchez-Vila et al., 2010). A review of the role of small scale concentration fluctuations in the interpretation of laboratory scale experiments is presented by Edery et al. (2012).

17 Solutes concentrations and/or physico-chemical variables (e.g., pH, electrical conductivity) are typically measured at the outlet of the flow cell (Chiogna et al., 2010), by sampling small volumes of water inside the porous material (Katz et al., 2010), or indirectly by image analysis of colorimetric reactions (Zinn et al., 2004; Jones \& Smith, 2005; Konz et al., 21 2009b). Monitoring at the outlet usually provides only information which is representative of 22 some cross-sectionally averaged behavior. Direct sampling within the flow cell cannot be repeated too frequently without significantly perturbing the flow and transport conditions, and

24 indirect measurements based on imaging techniques are limited to some specific solutes and reactions. 
1 To our knowledge, protocols for extensive direct measurements of concentrations and/or

2 physico-chemical parameters inside a porous medium have not been implemented, with the

3 exception of applications related to measurements of dissolved oxygen (Chiogna et al., 2010).

4 Although such measurements are not easy to accomplish, they are required to firmly ground

5 modeling interpretations on space distributed observation dynamics.

6 A key aim of this study is to present a set of laboratory-scale experimental tools and a

7 methodological approach conducive to an improved characterization of flow and transport

8 patterns within natural systems through continuous on-line measurements of parameters such

9 as $\mathrm{pH}$, redox potential (Eh) and electrical conductivity (EC). These local measurements are

10 performed inside the porous medium under imposed flow-through conditions. A user-defined

11 time resolution allows (a) obtaining detailed records of point breakthrough curve, and (b)

12 exploring a wide range of experimental time scales.

13 The two-dimensional (2D) experimental set-up, the mathematical model and the associated

14 numerical solution scheme employed to interpret the experimental evidences are presented in

15 Section 2. The main features of the three experiments performed are described in Section 3.

16 Section 4 is devoted to illustrating the modeling results.

17

\section{Materials, Methods and Modeling}

\subsection{Experimental set-up}

An Altuglas ${ }^{\circledR}$ flow cell (external dimensions: length 167-cm, width 68-cm, and thickness 4$\mathrm{cm}$ ) was divided into two compartments consisting of a 5-cm long inflow reservoir and a 152cm long compartment containing the porous medium (hereafter termed the 'tank') as depicted in Fig. 1. The two compartments were separated by an Altuglas ${ }^{\circledR}$ plate with porosity 0.37 
1 resulting from regularly spaced $8-\mathrm{mm}$ diameter holes. A $50-\mu \mathrm{m}$ nylon filter was used to

2 prevent the porous medium from invading the inflow reservoir. This inflow reservoir was

3 divided into two identical and independent sub-reservoirs to allow the simultaneous injection

4 of two different solutions in parallel. The injection into each sub-reservoir was performed by

53 tubes to optimize mixing inside the sub-reservoir and a Masterflex ${ }^{\circledR} \mathrm{L} / \mathrm{S}$ 2-channel

6 peristaltic pump to prevent flow rate differences between the sub-reservoirs. Six tubes

7 connect the outlet side of the tank to an outflow reservoir. The flow rate was regularly

8 controlled by on-line weighing of the solutions collected at the outflow.

9

10 The tank was filled up with glass beads (SiLibeads ${ }^{\circledR}$, Sigmund Lindner, GmbH), which had a 11 narrow size distribution and a diameter ranging from 0.5 to $0.75 \mathrm{~mm}$. Glass beads were used 12 rather than natural materials because natural materials are rarely pure and the occurrence of other minerals (e.g. micas, clays and iron oxy-hydroxides) even in small amounts may have a high reactivity with the injected chemical elements. The glass beads are completely composed of amorphous silica and have a low reactivity. The glass beads used for electrodes calibration and during the experiments have been previously washed with nitric acid $(0.1 \mathrm{~mol} / \mathrm{L})$ and rinsed five times with demineralized water. The upper plate of the tank contains seventeen holes to allocate single electrodes to provide on-line measurements of $\mathrm{pH}$, or Eh or EC inside the porous medium during the experiment (Fig. 1). These electrodes (Schott Instruments ${ }^{\circledR}$ ) have a diameter of $5 \mathrm{~mm}$ and are usually 21 employed for measurements in laboratory test tubes. The electrodes are placed at the middle of the porous medium layer after their calibration, and their impact on the flow is assumed to be negligible during data interpretation. The position of the electrodes in the tank is presented 24 in Fig. 1. The $\mathrm{pH}$ electrodes were calibrated using glass beads (the same as those in the tank) saturated with a pH 4 or $\mathrm{pH} 7$ buffer solutions. The redox potential electrodes were calibrated 
1 using glass beads saturated with $220 \mathrm{mV}$ standard solution and the conductivity electrodes

2 with $\mathrm{KCl} 0.01 \mathrm{~mol} / \mathrm{L}$ solution. The conductivity electrodes were composed of two plates of

3 platinum located inside a glass cylinder containing a small volume of solution. The EC

4 measured is directly correlated with the ability of the solution to conduct the current, which

5 depends on the ion concentration inside the volume of liquid between the two plates of

6 platinum.

7 Data acquisition is performed by a computer via 2 multi-parameter analyzers (Consort $\mathrm{NV}^{\circledR}$ ).

8 The recording rate for each electrode is one measurement per minute.

9

The glass beads were placed in the tank under fully saturated conditions to avoid air trapping.

11 The filling was performed according to the following three steps: (i) a layer of a few

12 centimeters of water was placed at the bottom of the tank, which was placed in a vertical position, (ii) wet glass beads were poured in the water until the level of the glass beads reached a level close to the free surface (about $1-2 \mathrm{~cm}$ below), and (iii) the tank walls were gently tapped with a rubber hammer to achieve tight packing of the porous medium without size segregation (Lewis \& Sjöstrom, 2010). The three steps are repeated until complete filling of the tank. A Neoprene sheet was placed on the porous medium before closing the tank with its cap to prevent preferential flow paths close to the cap.

The demineralized water, used for all experiments, was stored during $24 \mathrm{~h}$ in a 60 - $\mathrm{L}$ reservoir

21 before its injection into the tank. This prevents degassing due to temperature changes and 22 allows maintaining stable $\mathrm{pH}$ and Eh. 
2 A constant temperature of $22^{\circ} \mathrm{C}$ was maintained in the room during the experiments. The flow

3 rate was maintained as constant as possible to provide a Darcy velocity around $7.7 \times 10^{-6} \mathrm{~m} / \mathrm{s}$

$4 \quad(1.8 \mathrm{~m} / \mathrm{d}$, which can be considered as representative of natural conditions).

5

6

7

8

9

10

11

12

13

The following experiments were performed (Table 1):

1. Experiment 1, to test the electrical conductivity electrodes for a single fluid injection. A non-reactive solution of potassium chloride $\left(0.63 \mathrm{~g} / \mathrm{L}\right.$ or $\left.8.4610^{-3} \mathrm{~mol} / \mathrm{L}\right)$ was injected into the tank initially saturated with demineralized water at EC $=0.04 \mathrm{mS} / \mathrm{cm}$.

2. Experiment 2, to check the ability of the $\mathrm{pH}$ electrodes to respond to a wide variation in $\mathrm{pH}$ (between 10 and 1). A nitric acid solution at $\mathrm{pH}=1$ was injected while the porous medium was saturated by a sodium hydroxide solution at a concentration of $10^{-4} \mathrm{~mol} / \mathrm{L}$.

3. Experiment 3, with the injection of two fluids with different $\mathrm{pH}$ and $\mathrm{Eh}$ : a nitric acid solution colored in red by a food coloring agent (E 124) with $\mathrm{pH}=2$ and $\mathrm{Eh}=730$ $\mathrm{mV} / \mathrm{NHE}$ and a sodium hydroxide solution $\left(10^{-2} \mathrm{~mol} / \mathrm{L}\right)$ colored in blue by a food coloring agent (E 131) with a $\mathrm{pH}$ equal to 12 and $\mathrm{Eh}=260 \mathrm{mV} / \mathrm{NHE}$. The solutions had the same mass concentration of $0.63 \mathrm{~g} / \mathrm{L}$ to avoid density effects. It was necessary to add $\mathrm{KCl}$ to the sodium hydroxide solution to obtain the required mass concentration and maintain a concentration of $10^{-2} \mathrm{~mol} / \mathrm{L}$ in $\mathrm{NaOH}$. It was verified that both food coloring agents acted as conservative tracers. The porous medium was initially saturated by a solution of potassium chloride $\left(0.63 \mathrm{~g} / \mathrm{L}\right.$ or $\left.8.4610^{-3} \mathrm{~mol} / \mathrm{L}\right)$ at $\mathrm{pH} 7$ and $\mathrm{Eh}=595 \mathrm{mV} / \mathrm{NHE}$. 
1 The computer code TRACES (Transport of RadioActive Elements in Subsurface; Hoteit \&

2 Ackerer, 2004) was employed for the simulation of the experiments. TRACES is designed to

3 calculate flow and reactive transport in saturated porous media. It handles transient or steady

4 state computation in 2D or 3D heterogeneous domains and is based on mixed and

5 discontinuous finite element methods (Younes et al., 2010; Siegel et al., 1997).

6 The flow in the porous medium is described by the mass conservation equation and Darcy's

7 law and is assumed to be confined in $2 \mathrm{D}$ and at steady state.

9 It was assumed that transport at the tank scale could be modeled by the classical advection 10 diffusion/dispersion reaction equation (ADRE)

$11 \phi \frac{\partial \mathrm{C}_{\mathrm{i}}}{\partial \mathrm{t}}+\nabla \cdot\left(-\overline{\overline{\mathrm{D}}} \cdot \nabla \mathrm{C}_{\mathrm{i}}+\mathrm{qC}_{\mathrm{i}}\right)=\mathrm{r}$

12 where $\phi$ is the effective porosity (-), and $\overline{\bar{D}}$ is the diffusion/dispersion tensor $\left(\mathrm{L}^{2} / \mathrm{T}\right)$ defined by

$13 \quad \overline{\overline{\mathrm{D}}}=\phi \overline{\overline{\mathrm{D}}}_{\mathrm{m}}+\alpha_{\mathrm{T}}\|\mathrm{q}\| \cdot \delta_{\mathrm{ij}}+\frac{\left(\alpha_{\mathrm{L}}-\alpha_{\mathrm{T}}\right) \cdot \mathrm{q}_{\mathrm{x}} \cdot \mathrm{q}_{\mathrm{y}}}{\|\mathrm{q}\|}$

14 where $\alpha_{L}$ is the longitudinal dispersivity (L), $\alpha_{T}$ is the transverse dispersivity $(L), D_{m}$ is the 15 molecular diffusion $\left(\mathrm{L}^{2} / \mathrm{T}\right), \delta_{\mathrm{ij}}$ is he Kroenecker delta, $\mathrm{q}_{\mathrm{x}}$ and $\mathrm{q}_{\mathrm{y}}(\mathrm{L} / \mathrm{T})$ are the components 16 of the average Darcy's velocity along the $\mathrm{x}$ and $\mathrm{y}$ directions, respectively, $\mathrm{r}(\mathrm{mol} / \mathrm{T})$ is the 17 reaction rate and $\mathrm{C}_{\mathrm{i}}$ is the solute concentration $\left(\mathrm{mol} / \mathrm{L}^{3}\right)$ of species $\mathrm{i}$.

19 Following the pioneering work of Sanford and Konikow (1989) or more recent work on 20 reactive transport modeling (De Simoni et al., 2007, Hoffmann et al., 2010 among others), the 21 number of transport equations to solve can be reduced to avoiding excessive computer time.

22 The electrical conductivity is given by a linear combination of species concentrations

$23 \quad \mathrm{EC}=\sum_{\mathrm{i}} \lambda_{\mathrm{i}} \mathrm{C}_{\mathrm{i}}\left|\mathrm{z}_{\mathrm{i}}\right|$ 
1 where $\lambda_{i}$ is the ionic molar conductivity $\left(\mathrm{S} \mathrm{L}^{2} / \mathrm{mol}\right)$ and $z_{i}$ is the charge on the ion $i$.

2 If the species which constitute the solution are non-reactive, the EC can be used as state

3 variable in the $\mathrm{ADE}$ to simulate the changes of $\mathrm{EC}$ in the porous medium, i.e.,

$4 \phi \frac{\partial[\mathrm{EC}]}{\partial \mathrm{t}}+\nabla \cdot(-\overline{\overline{\mathrm{D}}} \cdot \nabla[\mathrm{EC}]+\mathrm{q}[\mathrm{EC}])=0$ which is rewritten as,

$5 \quad \phi \frac{\partial \sum_{\mathrm{i}}\left(\lambda_{\mathrm{i}} \mathrm{C}_{\mathrm{i}}\left|\mathrm{z}_{\mathrm{i}}\right|\right)}{\partial \mathrm{t}}+\nabla \cdot\left(\overline{\overline{-\mathrm{D}}} \cdot \nabla \sum_{\mathrm{i}}\left(\lambda_{\mathrm{i}} \mathrm{C}_{\mathrm{i}}\left|\mathrm{z}_{\mathrm{i}}\right|\right)+\mathrm{q} \sum_{\mathrm{i}}\left(\lambda_{\mathrm{i}} \mathrm{C}_{\mathrm{i}}\left|\mathrm{z}_{\mathrm{i}}\right|\right)\right)=0$. Since the transport equation is

6 linear in terms of concentration, we can write: $\sum_{\mathrm{i}} \lambda_{\mathrm{i}}\left|\mathrm{z}_{\mathrm{i}}\right|\left[\phi \frac{\partial \mathrm{C}_{\mathrm{i}}}{\partial \mathrm{t}}+\nabla \cdot\left(\overline{\overline{-\mathrm{D}}} \cdot \nabla \mathrm{C}_{\mathrm{i}}+\mathrm{qC}_{\mathrm{i}}\right)\right]=0$

8 Considering $\mathrm{pH}$ and $\mathrm{Eh}$ as state variables is an over simplification since they are log-scaled

9 values of concentrations. The solutions used (nitric acid and sodium hydroxide) are strong

10 acid and base and are considered as fully dissociated. The $\mathrm{pH}$ variations are computed by

11 writing the mass balance for $\mathrm{H}^{+}$and $\mathrm{OH}^{-}$as

12

$$
\left\{\begin{array}{l}
\phi \frac{\partial\left[\mathrm{H}^{+}\right]}{\partial \mathrm{t}}+\nabla \cdot\left(-\overline{\overline{\mathrm{D}}} \cdot \nabla\left[\mathrm{H}^{+}\right]+\mathrm{q}\left[\mathrm{H}^{+}\right]\right)=\mathrm{r} \\
\phi \frac{\partial\left[\mathrm{OH}^{-}\right]}{\partial \mathrm{t}}+\nabla \cdot\left(-\overline{\overline{\mathrm{D}}} \cdot \nabla\left[\mathrm{OH}^{-}\right]+\mathrm{q}\left[\mathrm{OH}^{-}\right]\right)=\mathrm{r} \\
{\left[\mathrm{H}^{+}\right] \cdot\left[\mathrm{OH}^{-}\right]=\mathrm{K}_{\mathrm{e}}}
\end{array}\right.
$$

13

where $r$ is the rate of the reaction which is assumed to take place at equilibrium and $K_{e}$ is the 14 equilibrium constant, which is the same for both ions. Following De Simoni et al. (2007), one 15 can write

$16\left\{\begin{array}{l}\phi \frac{\partial \mathrm{u}}{\partial \mathrm{t}}+\nabla \cdot(-\overline{\overline{\mathrm{D}}} \cdot \nabla \mathrm{u}+\mathrm{qu})=0 \\ \mathrm{u}=\left[\mathrm{H}^{+}\right]-\left[\mathrm{OH}^{-}\right] \\ {\left[\mathrm{H}^{+}\right] \cdot\left[\mathrm{OH}^{-}\right]=\mathrm{K}_{\mathrm{e}}}\end{array}\right.$ 
1 Therefore, the ADE is solved only once (for the state variable $\mathrm{u}$ ) and the concentrations of $\mathrm{H}^{+}$

2 and $\mathrm{OH}^{-}$are computed by

$3\left\{\begin{array}{l}{\left[\mathrm{H}^{+}\right]=\frac{\mathrm{u}+\sqrt{\mathrm{u}^{2}+4 \mathrm{~K}_{\mathrm{e}}}}{2}} \\ {\left[\mathrm{OH}^{-}\right]=\mathrm{K}_{\mathrm{e}} /\left[\mathrm{H}^{+}\right]}\end{array}\right.$

4 A similar approach is employed to compute Eh.

5

6 The domain considered for the simulation is a $1.52 \mathrm{~m} \times 0.58 \mathrm{~m}$ rectangle. The same grid of

710020 nodes and 20555 triangular elements is used for all the simulations. The characteristic

8 length of the grid elements is one centimeter. Some triangular elements were centered at the

9 observation points, and their surfaces can be considered as representative of the support

10 surface of the measures. Boundary and initial conditions are described in Table 1.

11 Values of effective porosity and longitudinal and transverse dispersivities were taken from

12 Konz et al. (2009a), who performed experiments at the same scale and with the same porous

13 material. The longitudinal dispersivity $\alpha_{L}$ was fixed to the average size of the glass beads,

14 and the transverse dispersivity was ten times lower. The value of the hydraulic conductivity

15 has no influence on the velocity field because the flow rate was prescribed for all the 16 experiments.

17 The parameters required for the simulations are summarized in Table 1. All simulations were 18 run without any further parameter calibration.

\section{Experimental results, simulations and discussion}

21 For experiment 1, electrical conductivities (EC) were measured by electrodes located at P6, 22 P8, P12, P13, P15, and P17 (see Fig. 1) at distances of 30, 50, 70, 70, 90 and $120 \mathrm{~cm}$, 23 respectively, from the inlet. 
1 The temporal evolution of the EC at electrodes P6, P12, P13, and P17, which are

2 representative of the EC changes in the tank, is depicted in Fig. 2. The fronts are not as sharp

3 as expected and display some tailings before reaching a constant value. The breakthrough

4 curves for the two electrodes located at the same distance (P12 and P13) from the inlet are

5 very similar, showing that the packing of the porous material was quite homogeneous. At

6 steady state conditions for all electrodes, the measured values of the EC range between 0.54

7 to $0.56 \mathrm{mS} / \mathrm{cm}$, which is below the EC of the solution measured in the inlet reservoir (1.38

$8 \mathrm{mS} / \mathrm{cm}$ ). These underestimates are due to the presence of the porous medium. A linear

9 relationship between the EC in a solution with or without the presence of a given porous

10 medium was found for this kind of electrode by additional experiments. The coefficient of

11 proportionality can be estimated by comparing the EC of the injected solution and the value

12 reached in the porous material at steady state.

13 The numerical simulations were run using the parameters and initial and boundary conditions

14 described in Table 1. The arrival times were well reproduced, and the computed values display a sharp front as expected (Fig. 2). However, the agreement between the measured and computed EC remains quite poor. These discrepancies are assumed to be due to mixing

17 between the entering fluid and the fluid located inside the glass cylinder of the electrode. The

18 simulations also assume that mixing in this small reservoir can be considered instantaneous.

19 The solute mass balance in this reservoir is given by

$20 \quad \mathrm{v} \frac{\partial \mathrm{C}_{\mathrm{r}}}{\partial \mathrm{t}}=\mathrm{Q}\left(\mathrm{C}-\mathrm{C}_{\mathrm{r}}\right)$

21 where $\mathrm{v}$ is the volume of water in the cylinder, $\mathrm{Q}$ is the flow rate through the reservoir and $\mathrm{C}_{\mathrm{r}}$

22 is the solute concentration in the reservoir. As previously noted, since the model is linear in 23 concentration, EC can be used as a state variable and $\mathrm{C}_{\mathrm{r}}$ represents the measured EC. 
1 The flow rate $\mathrm{Q}$ was estimated by multiplying the flow velocity in the porous medium by the

2 cross sectional area of the capture zone due to the device entrance hole. Since the glass beads

3 were filling the electrode reservoir, we assumed that the area of the capture zone coincides

4 with the hole's area. The electrode characteristics were measured for several tested electrodes.

5 The volume of the cylinder was equal to $0.188 \mathrm{~cm}^{3}$ and the diameters of the holes ranges

6 between 0.10 and $0.12 \mathrm{~cm}$.

7 The EC inside the reservoir is computed by convolution with the EC simulated by TRACES 8 as input signal, i.e.

$9 \quad \mathrm{EC}_{\mathrm{r}}(\mathrm{t})=\int_{0}^{\mathrm{t}} \mathrm{EC}_{\mathrm{s}}(\tau) \mathrm{e}^{-\mathrm{Q}(\mathrm{t}-\tau) / \mathrm{v}} \mathrm{d} \tau$

10 The simulations were run with a diameter of the hole of $0.10 \mathrm{~cm}$ and porosity inside the 11 reservoir equal to the porosity in the porous medium. Considering mixing dynamics inside the reservoir highly improves significantly the quality of the simulation results (Fig. 2).

14 Fig. 3 shows the pH evolution during experiment 2 at the four electrodes P7, P9, P14 and P16, located at 40, 60, 90 and $110 \mathrm{~cm}$, respectively, from the injection (Fig. 1). Modeling of the $\mathrm{pH}$ fronts inside the tank leads to good results without any parameter calibration (Fig. 3).

The measurements at the $\mathrm{Eh}$ and $\mathrm{pH}$ electrodes can be relevant to study the transport of different solutes in porous media. Experiment 3 was aimed at studying the mixing of two different fluids. Two solutions with different $\mathrm{pH}$ and Eh were injected in the system (see Table 1). We focus on the $\mathrm{pH}$ values measured at $10 \mathrm{~cm}$ from the injection and following three locations (Fig 1.):

- P1, located on the side in which the basic solution was injected; 
- $\quad$ P2, at the middle of the tank, at the interface of both solutions;

- P3, positioned on the side where the acid solution was injected.

3 The changes of $\mathrm{pH}$ were observed simultaneously for the electrodes P1 and P3 (Fig. 4). The

4 electrode located at the interface $(\mathrm{P} 2)$ reached a value close to neutrality, as expected. The 5 interface zone, colored in violet, is clearly visible in Fig. 5. Interestingly, the fronts do not 6 appear as sharp as those observed in experiment 2, and the $\mathrm{pH}$ value at the interface is not as 7 stable as the values observed at the two other electrodes. Despite the small thickness of the interface, the $\mathrm{pH}$ electrodes we employed were able to record a $\mathrm{pH}$ around 7 , revealing the acid-base reaction between nitric acid and sodium hydroxide.

The simulation is in good agreement with the observed transport dynamics of the acid. The tailing observed in the basic part of the tank and the $\mathrm{pH}$ value at the interface could not be reproduced with the ADRE model. This could be due to some uncertainties in the experimental conditions, such as small differences in the in-fluxes between the two inlet reservoirs and/or the position of the electrode. The impact of such differences on inlet fluxes on the modeling of laboratory scale scenarios has been described by Fajraoui et al. (2011) through global sensitivity analyses techniques.

Electrodes of redox potential were also inserted into the porous medium during the same experiment. Although the experimental conditions are not optimal for the electrodes (no redox reactions), the electrodes were tested with the same solutions employed in experiment 3

21 (nitric acid and sodium hydroxide solutions), which display redox potential differences (260 $\mathrm{mV} / \mathrm{NHE}$ for the acid solution and $730 \mathrm{mV} / \mathrm{NHE}$ for the basic solution). The results at four selected electrodes are presented in Fig. 6. Electrodes at P5 and P11 (resp. at P4 and P10)

24 were positioned on the side of the tank where the injection of $\mathrm{HNO}_{3}$ (resp. $\mathrm{NaOH}$ ) at $10^{-2}$ $\mathrm{mol} / \mathrm{L}$ was performed, at 20 and $65 \mathrm{~cm}$, respectively, from the injection. 
1 The changes in the Eh started approximately at the same time for the electrodes located at the

2 same distance from the inlet (P4 and P5, P10 and P11). Asymptotic values obtained in the

3 sodium hydroxide solution were close for both electrodes (258 and $264 \mathrm{mV} / \mathrm{NHE}$ ) and in

4 good agreement with the value measured in the solution within the injection tank. Similar

5 results were obtained for the acid solution, and similar Eh were measured for both electrodes

6 (748 and $751 \mathrm{mV} / \mathrm{NHE}$ ), which are close to the injection region. The Eh front displays

7 significant tailing effects when compared to the $\mathrm{pH}$ fronts. Moreover, for both $\mathrm{pH}$ and $\mathrm{Eh}$, the

8 tailing was more significant at $0<\mathrm{y}<29$ than within other regions in the tank.

9 As expected, the simulations did not succeed in reproducing these tailings (Fig. 6). If the 10 previously mentioned uncertainties still have an effect on the results, the tailing is significantly more important for the Eh than it is for $\mathrm{pH}$ for the same experimental conditions. Two additional points can be considered to explain the behavior of Eh: (i) the design of the electrodes, which did not allow the on-line measurements of the redox potential in the presence of abrupt changes in time, and (ii) some additional processes, which remain unknown. However, the observations were made at a considerable distance from the interface, suggesting that the first assumption is the most likely.

\section{Conclusions}

20 Improved understanding of reactive transport in saturated media is a necessary step to assess 21 mathematical and numerical models. Experiments at the laboratory scale may avoid model calibration, allow a good control of initial and boundary conditions and therefore provide observations which are well suited for model verification.

24 New experiments in a 2D saturated porous material were presented. It was shown that 
1 - 2D experimental set-ups can be used with on-line measurements of the electrical 2 conductivity and $\mathrm{pH}$ inside a saturated porous media.

3 - Electrodes with an internal reservoir can considerably change the apparent concentration evolution due to mixing inside this reservoir, which can lead to erroneous interpretation of the transport phenomena.

6 - EC can be considered as a state variable obeying the conservative transport equation. Simulating evolution of $\mathrm{pH}$ requires solving a classical ADE, as detailed in section 2.3 .

- The evolution of the redox potential displayed some tailing, probably due to the characteristic time required by the electrode to obtain a stable value. Therefore, with the electrodes used in this set-up, it was not possible to characterize the sharp redox

The authors gratefully acknowledge the financial support of the High Council for Scientific and Technological Cooperation between France-Israel (Project Research

18 Networks Program in Water Science, Resources Management) and Prof. A. Guadagnini, 19 Politcnico di Milano for helpful discussions.

20 The described data set can be obtained by simple request. 


\section{5. References}

4 André, C., Sardin, M., Vitorge, P., Faure, M-H., 1998. Analysis of breakthrough curves of

$5 \quad \mathrm{~Np} \_\mathrm{V} /$ in clayey sand packed column in terms of mass transfer kinetics. J. Contam. Hydrol., $6 \quad 35,161-173$.

7 Bauer, R.D., Maloszewski, P., Zhang, Y., Meckenstock, R.U., Griebler, C., 2008. Mixing8 controlled biodegradation in a toluene plume - Results from two-dimensional laboratory 9 experiments. J. Contam. Hydrol., 96, 150-168.

Burris, D.R., Hatfield, K., Wolfe, N.L., 1996. Laboratory experiments with heterogeneous

11 reactions in mixed porous media. J. Environ. Eng., 122, (8), 685-691.

Carrayrou, J., Hoffmann, J., Knabner, P., Kräutle, S., De Dieuleveult, C., Erhel, J., Van der Lee, J., Lagneau, V., Mayer, U., MacQuarrie, K., 2010. Comparison of numerical methods for simulating strongly nonlinear and heterogeneous reactive transport problems - the MoMaS benchmark case. Computat. Geosci., 14, (3), 483-502.

Chiogna, G., Eberhardt, C., Grathwohl, P., Cirpka, O.A., Rolle, M., 2010. Evidence of Compound-Dependent Hydrodynamic and Mechanical Transverse Dispersion by Multitracer Laboratory Experiments. Environ. Sci. Technol., 44, (2), 688-693.

De Simoni, M., Carrera, J., Sanchez-Vila, X., Guadagnini, A., 2007. A procedure for the solution of multicomponent reactive transport problems. Water Resour. Res., 41, 1-16.

Edery, Y., Scher, H., Berkowitz, B., 2009. Modeling bimolecular reactions and transport in porous media. Geophys. Res. Lett., 36, L02407, doi:10.1029/2008GL036381.

Edery, Y., Scher, H., Berkowitz, B., 2010. Particle tracking model of bimolecular reactive transport in porous media. Water Resour. Res., 46, W07524, doi:10.1029/2009WR009017. 
1 Edery, Y., Guadagnini, A., Sher, H. Berkowitz, B., 2012. Reactive transport in disordered

2 media: role of fluctuations in interpretation of laboratory experiments. Adv. Water Resour., 3 doi:10.1016/j.advwatres.2011.12.008.

4 Fahs, M., Younes, A., Delay, F., 2009. On the use of large time steps with ELLAM for 5 transport with kinetic reactions over heterogeneous domains. AIChE J., 55, (5), 1121-1126.

6 Fajraoui N., Ramasomanana F., Younes A., Mara T., Ackerer P., Guadagnini A., 2011. Use of 7 Global Sensitivity Analysis and Polynomial Chaos Expansion for Interpretation of Non8 reactive Transport Experiments in Laboratory-Scale Porous Media. Water Resour. Res., 47, 9 W02521, doi: 10.1029/2010WR009639. Gramling, C.M., Harvey, C.F., Meigs, L.C., 2002. Reactive transport in porous media: A 11 comparison of model prediction with laboratory visualization. Environ. Sci. Technol., 36, 12 (11), 2508-2514.

13 Gandhi, S., Oh, B-T., Schnoor, J.L., Alvarez, P.J.J., 2002. Degradation of TCE, Cr(VI), 14 sulfate, and nitrate mixtures by granular iron in flow-through columns under different microbial conditions. Water Res., 36, 1973-1982.

Grolimund, D., Borkovec, M., 2006. Release of colloidal particles in natural porous media by monovalent and divalent cations. J. Contam. Hydrol., 87, 155-175.

Hoffmann J., Kräutle S., Knabner P., 2010, A parallel global-implicit 2-D solver for reactive transport problems in porous media based on a reduction scheme and its application to the MoMaS benchmark problem. Comput Geosci (2010) 14:421-433, doi 10.1007/s10596-0099173-7

Hoteit, H., Ackerer, P., 2004. TRACES Transport of RadioActive Elements in Subsurface, 23 User's guide v1.20, $70 \mathrm{p}$. 
1 Jones, E.H., Smith, C.C., 2005. Non-equilibrium partitioning tracer transport in porous media:

2 2-D physical modelling and imaging using a partitioning fluorescent dye. Water Res., 39, $3 \quad 5099-5111$.

4 Katz, G.E., Berkowitz, B., Guadagnini, A., Saaltink, M.W., 2010. Experimental and modeling 5 investigation of multicomponent reactive transport in porous media. J. Contam. Hydrol., 6 doi:10.1016/j.jconhyd.2009.11.002.

7 Kinzelbach, W., Schafer, W., Herzer, J., 1991. Numerical modeling of natural and enhanced 8 denitrification processes in aquifers. Water Resour. Res., 27, (6), 1123-1135.

9 Konz, M., Ackerer, P., Younes, A., Huggenberger, P., Zechner, E., 2009a. 2D stable layered laboratory-scale experiments for testing density-coupled flow models. Water Resour. Res., 11 45, doi:10.1029/2008WR007118.

Konz, M., Ackerer, P., Huggenberger, P., Veit, C., 2009b. Comparison of light transmission and reflection techniques to determine concentrations in flow tank experiments. Exp. Fluids., $14 \quad 47,85-93$. Lewis, J., Sjöstrom, J., 2010. Optimizing the experimental design of soil columns in saturated and unsaturated transport experiments. J. Contam. Hydrol., 115, 1-13.

Rolle, M., Eberhardt, C., Chiogna, G., Cirpka, O.A., Grathwohl, P., 2009. Enhancement of dilution and transverse reactive mixing in porous media: Experiments and model-based interpretation. J. Contam. Hydrol., 110, 130-142.

20 Saaltink, M.W., Carrera, J., Ayora, C., 2001. On the behavior of approaches to simulate reactive transport. J. Contam. Hydrol., 48, 213-235.

Sanchez-Vila X., Fernàndez-Garcia, D., Guadagnini, A., 2010. Interpretation of column experiments of transport of solutes undergoing an irreversible bimolecular reaction using a continuum approximation. Water Resour. Res., 46, W12510, doi:10.1029/2010WR009539. 
1 Sanford, W., Konikow, L., 1989. Simulation of calcite dissolution and porosity changes in

2 saltwater mixing zones in coastal aquifers. Water Resour. Res., 25, (4), 655-667.

3 Siegel, P., Mosé, R., Ackerer, P., Jaffre, J., 1997. Solution of the advection-diffusion equation

4 using a combination of discontinuous and mixed finite elements. Int. J. Num. Methods in

5 Fluids, 24, (6), 595-613.

6 Su, C., Puls, R.W., 2004. Significance of Iron (II,III) Hydroxycarbonate Green Rust in

7 Arsenic Remediation Using Zerovalent Iron in Laboratory Column Tests. Environ. Sci.

8 Technol., 38, 5224-5231.

9 Steefel, C., DePaolo, D., Lichtner, P., 2005. Reactive transport modeling: An essential tool 10 and a new research approach for the Earth sciences. Earth Planet. Sc. Lett., 240, (3-4), 53911558.

Van der Lee, J., De Windt, L., Lagneau, V., Goblet, P., 2003. Module-oriented modeling of 13 reactive transport with HYTEC. Comp. Geosci., 29, 265-275.

14 Walter, A.L., Frind, E.O., Blowes, D.W., Ptacek, C.J., Molson, J.W., 1994. Modeling of 15 multicomponent reactive transport in groundwater 1. Model development and evaluation. Water Resour. Res., 30, (11), 3137-3148.

17 Yeh, G.T., Tripathi, V.S., 1991. Model for simulating transport of reactive multispecies 18 components - model development and demonstration. Water Resour. Res., 27, (12), 3075193094.

20 Younes, A., Ackerer, P., Delay, F., 2010. Mixed finite element for solving diffusion-type 21 equations. Rev. Geophys., 48, RG1004, doi:10.1029/2008RG000277.

Zinn, B., Meigs, L.C., Harvey, C.F., Haggerty, R., Peplinski, W.J., Von Schwerin, C.F., 2004. 
1 Dimensional Conductivity Fields with Connected Regions of High Conductivity. Environ.

2 Sci. Technol., 38, 3916-3926.

3

4

5

6 


\section{Figure Captions}

2

3 Fig. 1: (a) Experimental set-up and (b) top-view of the set-up with the potential position of the

4 different electrodes (open circle).

5

6 Fig. 2. Experiment 1: Measured (dots) and computed (lines) EC versus time during injection

7 of $\mathrm{KCl}$ solution, without "mixing" effects (dashed lines) and with "mixing" effects 8 (continuous lines).

9

10 Fig. 3. Experiment 2: Measured (dots) and computed (lines) $\mathrm{pH}$ versus time during injection 11 of nitric acid solution.

12

13 Fig. 4. Experiment 3: Measured (dots) and computed (lines) $\mathrm{pH}$ versus time during an acido14 basic reactive transport.

15

16 Fig. 5. Experiment 3: Electrodes monitoring during reactive transport: photograph showing 17 the interface zone between red acid solution and blue sodium hydroxide solution.

18

19 Fig. 6. Experiment 3: Measured (dots) and computed (lines) Eh versus time during a

20 simultaneously injection of nitric acid and sodium hydroxide solutions. 
1 Table 1: Parameters for the simulations

\begin{tabular}{ll}
\hline Domain size & $1.52 \times 0.58 \mathrm{~m}$ \\
Hydraulic conductivity: $\mathrm{K}$ & $3.34 \times 10^{-3} \mathrm{~m} / \mathrm{s}$ \\
Effective porosity: $\phi$ & 0.375 \\
Longitudinal dispersivity: $\alpha_{\mathrm{L}}$ & $0.0008 \mathrm{~m}$ \\
Transverse dispersivity: $\alpha_{\mathrm{T}}$ & $0.00008 \mathrm{~m}$ \\
Molecular diffusion $\mathrm{D}_{\mathrm{m}}:$ & $1.0 \times 10^{-09} \mathrm{~m}^{2} / \mathrm{s}$ \\
\hline Experiment 1. & $\mathrm{H}=0.25 \mathrm{~m}$ \\
Inflow boundary condition & $\mathrm{q}_{\mathrm{L}}=7.60 \mathrm{x} 10^{-6} \mathrm{~m} / \mathrm{s}$ \\
Outflow boundary condition & $\mathrm{C}_{0}=0.04 \mathrm{mS} / \mathrm{cm}(\mathrm{Cond})$ \\
Initial condition & $\mathrm{C}_{\mathrm{L}}=0.5546 \mathrm{mS} / \mathrm{cm}(\mathrm{Cond})$ \\
Upstream boundary condition & $\mathrm{H}=0.25 \mathrm{~m}$ \\
\hline Experiment 2. & $\mathrm{q}_{\mathrm{L}}=7.33 \mathrm{x} 10^{-6} \mathrm{~m} / \mathrm{s}$ \\
Inflow boundary condition & $\mathrm{C}_{0}=10(\mathrm{pH})$ \\
Outflow boundary condition & $\mathrm{C}_{\mathrm{L}}=1(\mathrm{pH})$ \\
Initial condition & $\mathrm{H}=0.25 \mathrm{~m}$ \\
Upstream boundary condition & $\mathrm{q}_{\mathrm{L}}=7.63 \times 10^{-6} \mathrm{~m} / \mathrm{s}$ \\
\hline Experiment 3. & $\mathrm{C}_{0}=7(\mathrm{pH})$ \\
Inflow boundary condition & $\mathrm{C}_{\mathrm{L}}(0.0 \leq \mathrm{y}<0.29)=12(\mathrm{pH})$ \\
Outflow boundary condition & $\mathrm{C}_{\mathrm{L}}(0.29 \leq \mathrm{y} \leq 0.58)=2(\mathrm{pH})$ \\
Initial condition & $\mathrm{C}_{0}=595 \mathrm{mV}(\mathrm{Eh})$ \\
Upstream boundary condition & $\mathrm{C}_{\mathrm{L}}(0.0 \leq \mathrm{y}<0.29)=730 \mathrm{mV}(\mathrm{Eh} / \mathrm{NHE})$ \\
Initial condition & $\mathrm{C}_{\mathrm{L}}(0.29 \leq \mathrm{y} \leq 0.58)=260 \mathrm{mV}(\mathrm{Eh} / \mathrm{NHE})$ \\
Upstream boundary condition & \\
\hline
\end{tabular}




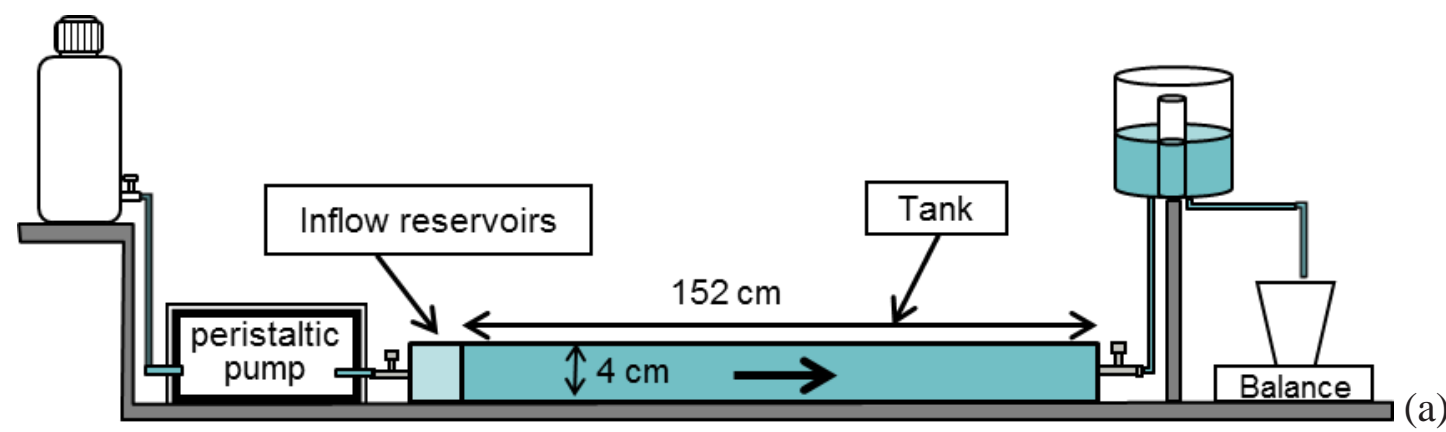

4

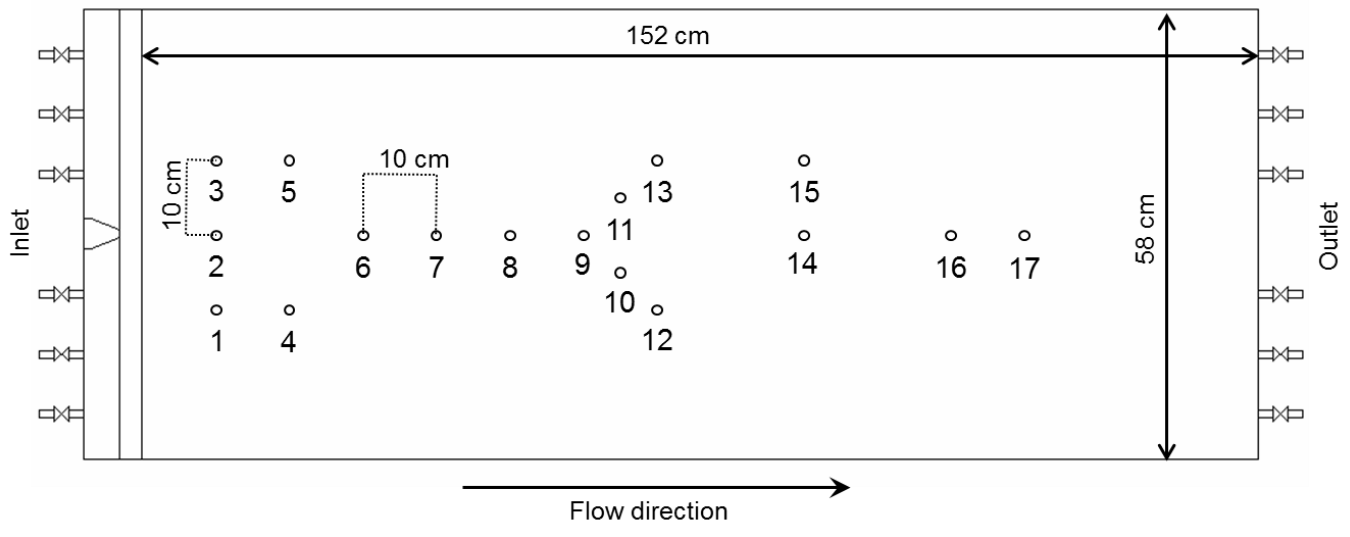

(b)

6 Fig. 1: (a) Experimental set-up and (b) top-view of the set-up with the potential position of

7 the different electrodes (open circle).

8

9

10

11 


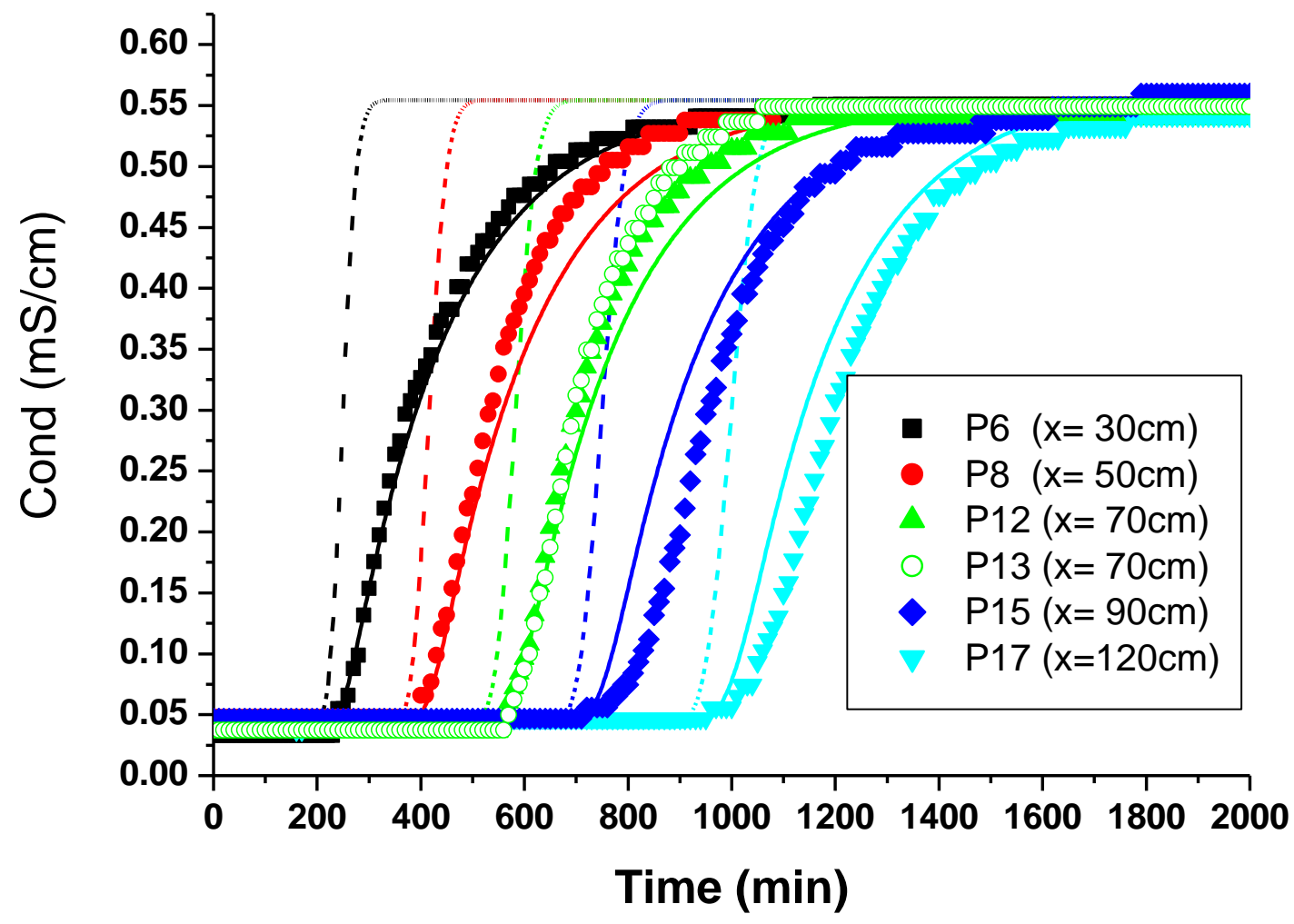

1

2 Fig. 2. Experiment 1: Measured (dots) and computed (lines) EC versus time during injection 3 of $\mathrm{KCl}$ solution, without "mixing" effects (dashed lines) and with "mixing" effects 4 (continuous lines). 


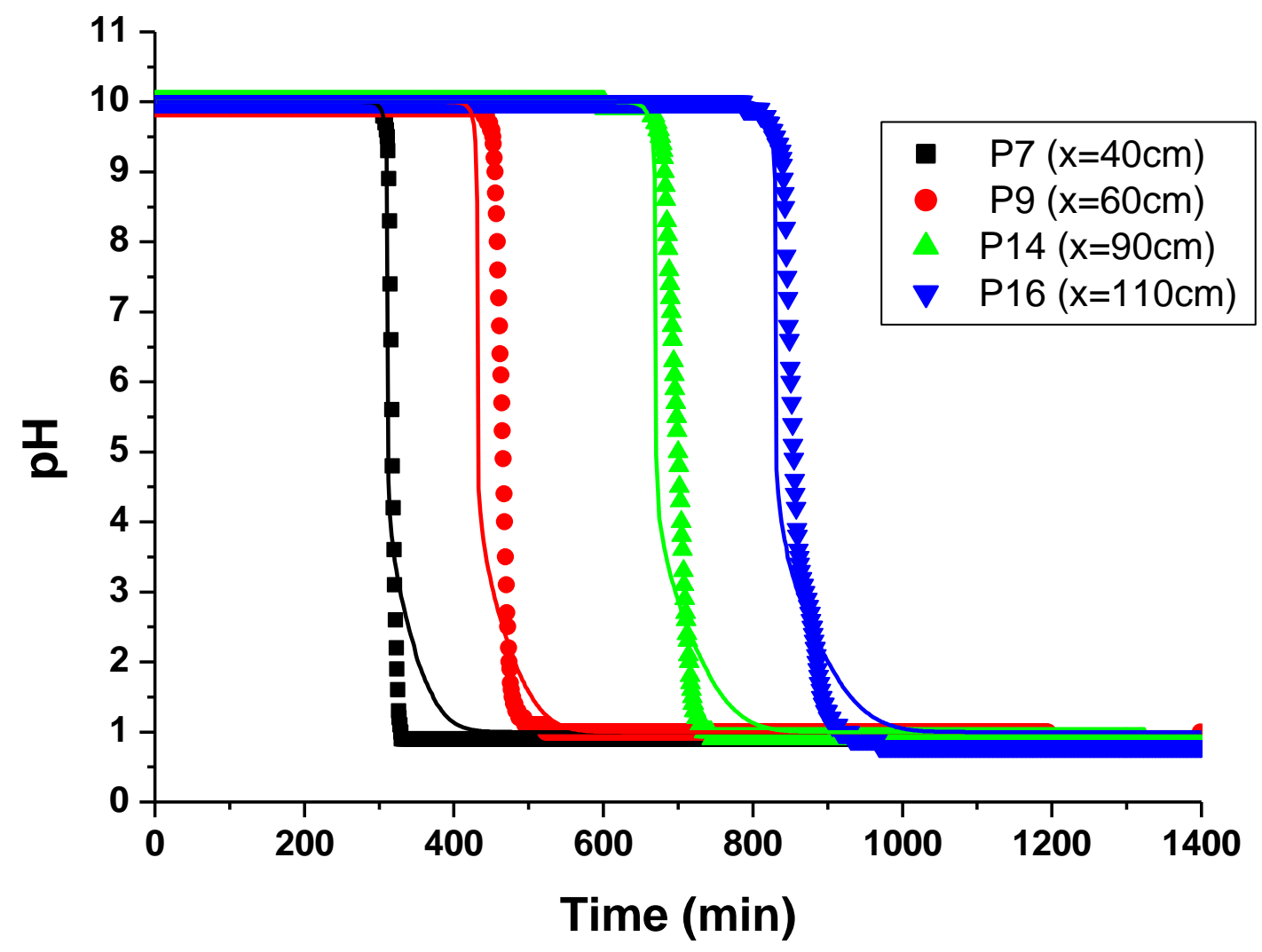

1

2 Fig. 3. Experiment 2: Measured (dots) and computed (lines) $\mathrm{pH}$ versus time during injection 3 of nitric acid solution.

4

5

6

7 


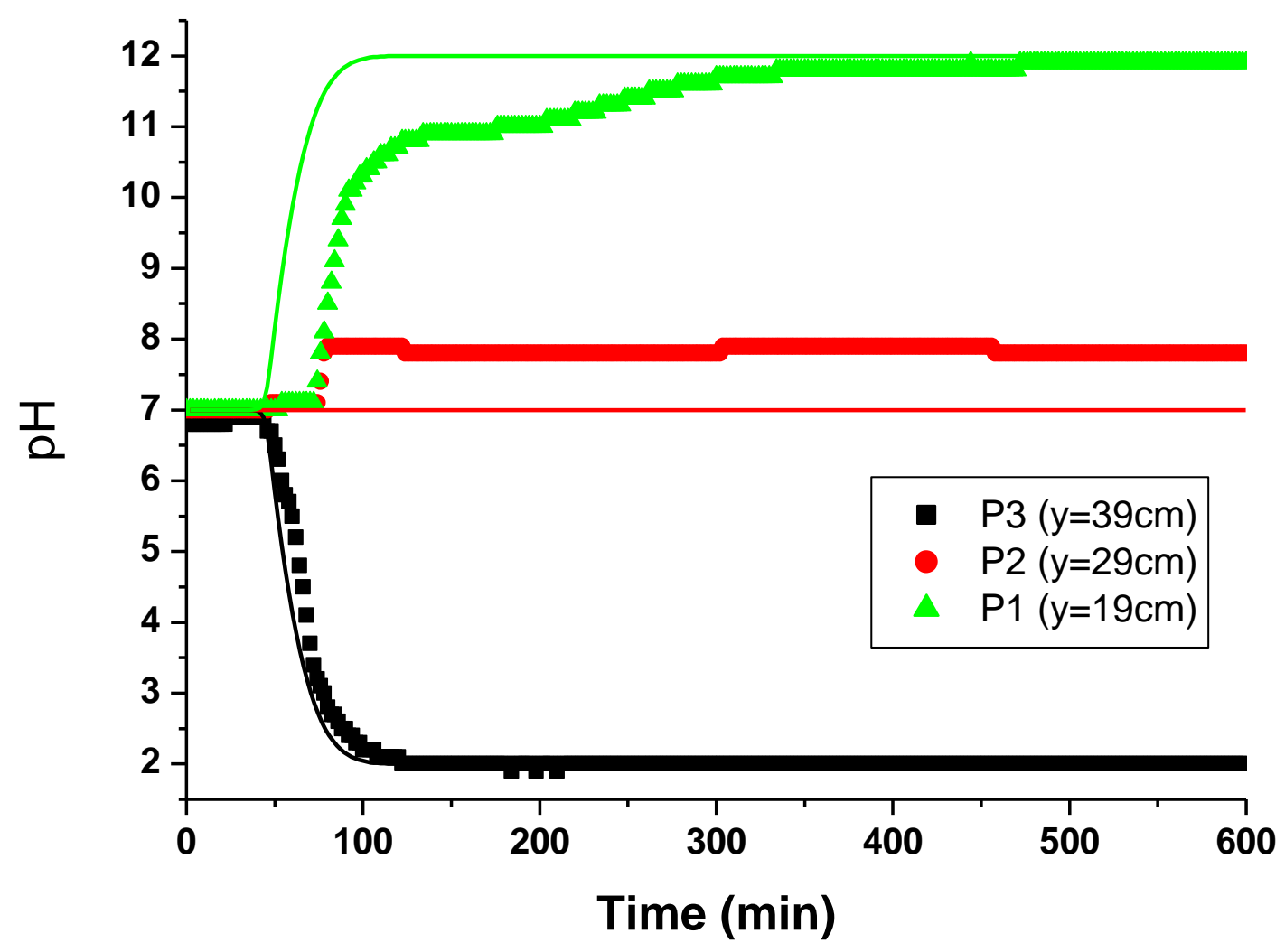

2

3 Fig. 4. Experiment 3: Measured (dots) and computed (lines) $\mathrm{pH}$ versus time during an acido-

4 basic reactive transport.

5 


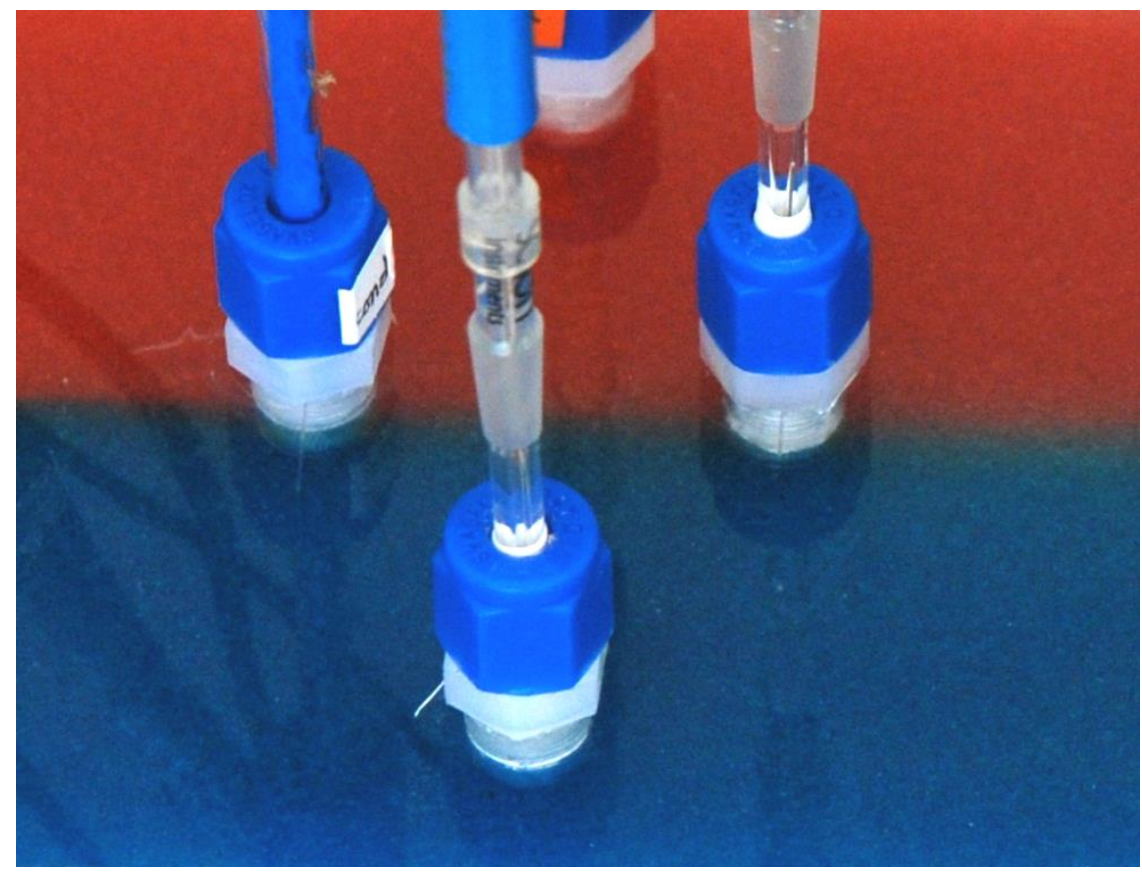

1 Fig. 5. Experiment 3: Electrodes monitoring during reactive transport: photograph showing

2 the interface zone between red acid solution and blue sodium hydroxide solution.

3

4

5

6 


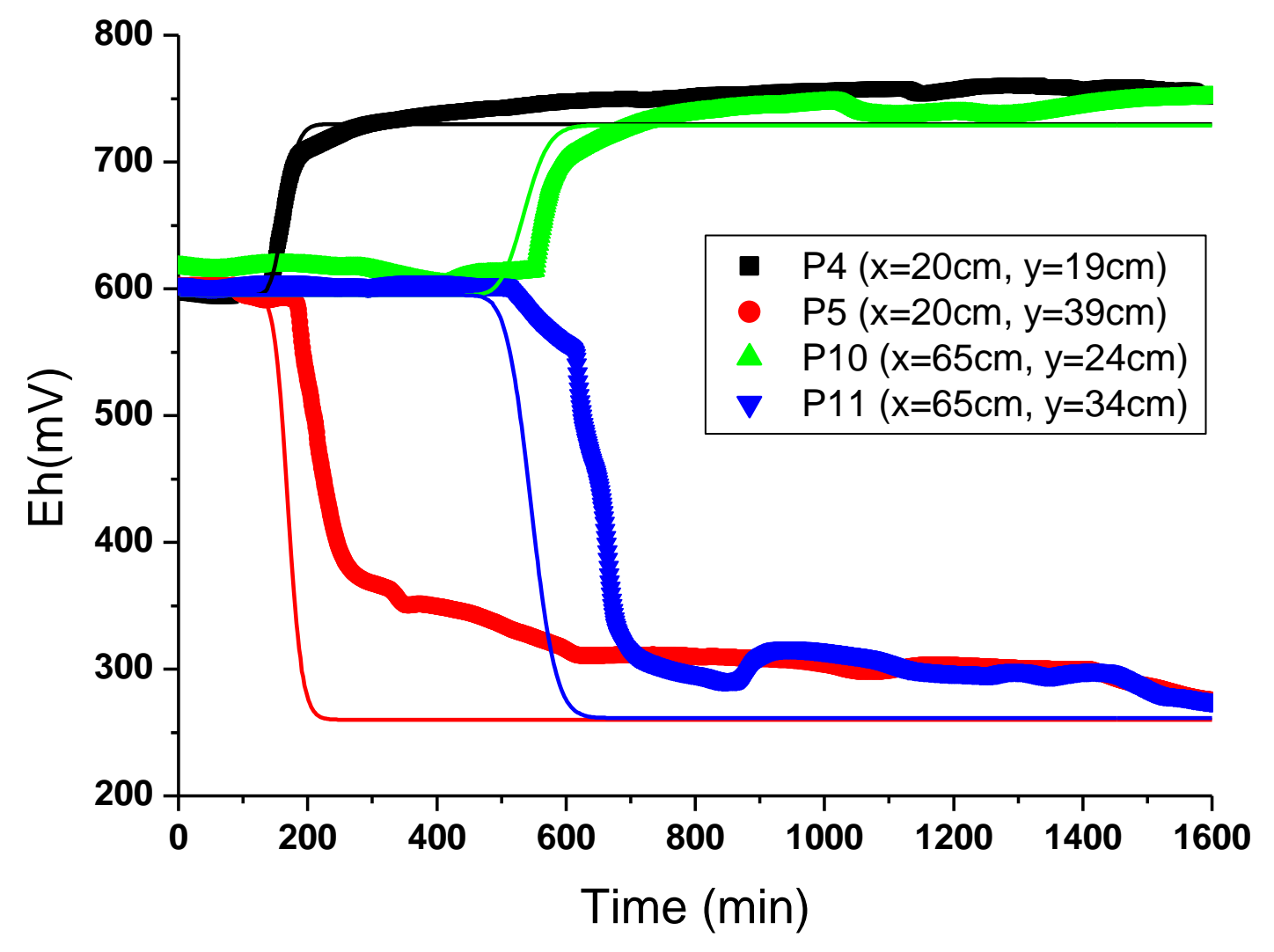

3

4 Fig. 6. Experiment 3: Measured (dots) and computed (lines) Eh versus time during a 5 simultaneously injection of nitric acid and sodium hydroxide solutions.

6

7

8 